\title{
Encyclopedic Palace
}

\author{
LUDOVICA MAZZETTI D’ALBERTIS, La Sapienza University, Italy
}

In the last decades the world has become rapidly smaller with the destruction of spatial barriers known as "globalization." It is a term both annoying and exhaustive, signifying a syncretic and global perception of reality. This condition has been further made easy by the enormous amount of data made accessible to us. The accelerated transition from an analogue to a digital world has literally invaded us with information creating not only a huge cultural gap between generations, with all its consequences, but offering at the same time huge opportunities. This paper intends to describe how technology, not without obstacles, has changed the way to communicate culture, and to make it more accessible. Our cultural heritage requires technology to be known and furthermore in order to be preserved. Present archives and museums, whether large or small, must move along with times, giving large space to technology and to new professional skills. The protection of our heritage requires communication, which plays a decisive role in making everybody knowledgeable. It is paradigmatic today and a duty to use technologies in order to store, preserve, save and communicate this heritage.

Key words:

Archives, Art, Multimedia Exhibitions, Virtual Exhibitions, Virtual Museums.

SDH Reference:

Ludovica Mazzetti D’Albertis. 2018. Encyclopedic Palace. SDH, 2, 1, 80-94.

DOI : $10.14434 /$ sdh.v2i1.24611

\section{INTRODUCTION}

Paul Saffo, a technology forecaster based in Silicon Valley and Consulting Professor in the School of Engineering at Stanford University stated in 1997: "It's my belief that technology does not drive change. Technology merely enables changes. It creates options and opportunities that as individuals and as communities and as entire cultures we choose to exploit. And it's our response to the technologies that drive change. In other words, first we invent our technologies and then we use our technologies to reinvent ourselves" [Adler 1997].

Understanding the history of art in all of its forms requires a privileged access to the knowledge of the history of cultures. The artistic product is only a synthesis between subjective and objective reality-and by "objective" we mean the historical, social, economic and cultural context of its production. New technologies are the instruments by which artists express themselves. Art has used advanced technology for decades; we need only to think of the pioneers of video art as Nam June Paik and of the use of electronic images in the 1960s. For years we have been witnessing beautiful installations by important contemporary artists such as Bill Viola, Pipilotti Rist and many others.

Author's address: Ludovica Mazzetti D’Albertis, Art History and Performing Arts Department, Piazzale Aldo Moro 5, Rome, Italy; email: ludomaz@yahoo.it

(c) [2018] by the author; licensee Studies in Digital Heritage, IU, Bloomington (IN), USA. This article is an open access article distributed under the terms and conditions of the Creative Commons Attribution License (CC BY-NC) 
This writer will never forget the incredible effect of the video Homo Sapiens Sapiens projected onto the vault of San Stae at the 2005 Venice Biennale. The video flickered and canceled the Baroque architectural space: a dreamlike show that the public could view while reclining on armchairs. The total involvement of this show reminded us of the works of the great Baroque artists the Church commissioned to represent epiphanies celebrating the Christian dogmas in response to Protestantism. Magnificent frescoes then reduced the space, creating amazing "trompe l'oeil," "horror vacui," and scenography to serve the glory of the Church that was losing its power to persuade and was forced to use as expedients the incredible projects of famous masters of illusion: examples are the Triumph of the Name of Jesus (Fig. 1) on the vault of Gesù church in Rome painted by "Baciccio," Giovan Battista Gaulli (1639-1709), or the Apotheosis of St. Ignatius (Fig. 2) by Andrea Pozzo (16421709) in another Roman church, Sant'Ignazio di Loyola.

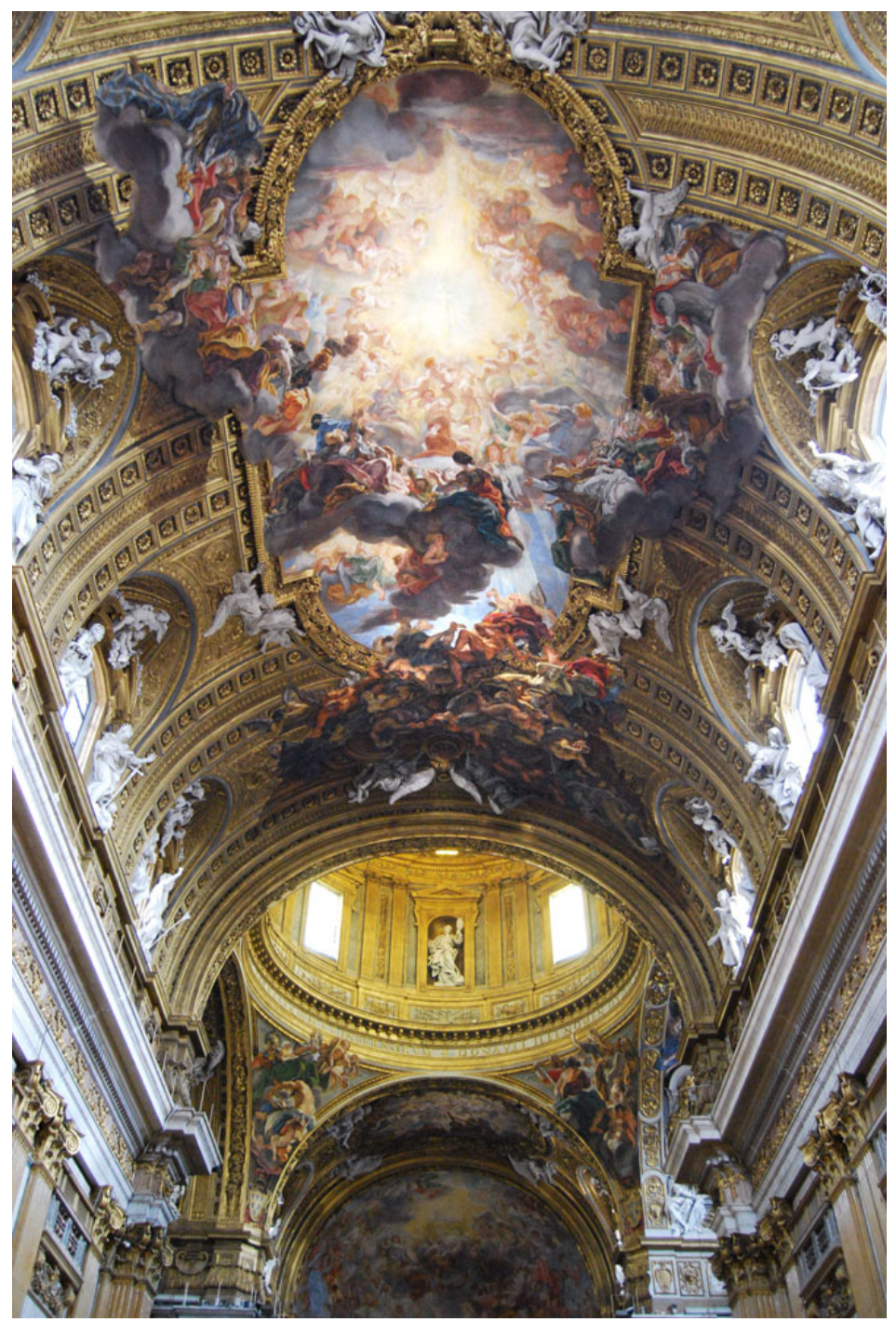

Figure 1. Giovan Battista Gaulli, The Triumph of the Name of Jesus, (1672-1675). 


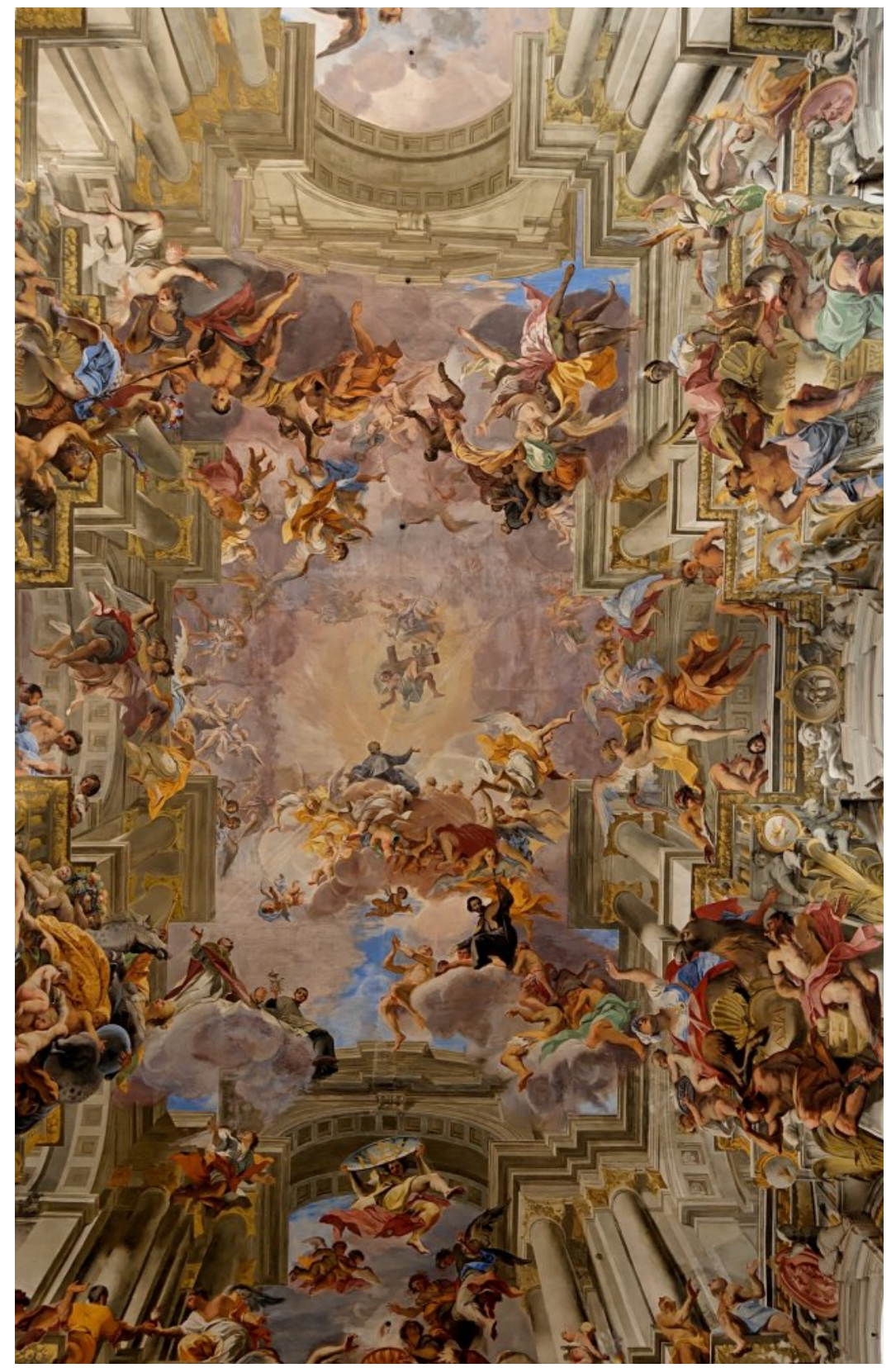

Figure 2. Andrea Pozzo, Apotheosis of St. Ignatius, (1691-1694).

Over the years, the tools available to art in all its forms have become incredibly more sophisticated, and these same tools can be used by those who valorize art and cultural heritage as an economic and social strategy. The protection of our heritage has to be supported by communication, which comes to play a decisive role in the awareness of the layman. The language of art has changed; now the 
curators must do the same. Today it becomes a paradigm and a duty to use technologies to store, preserve, save and communicate.

\section{STORE}

"Italy, whose archiving rules have finally take-off, should develop them and use them for the multitude of Italian archives in order to minimize the threats represented by the chance and the lack of care for the preservation of present and past memories. Memories that more of any other should be considered as sacred ones!" [Casanova 1928]. These words, written in 1928, are still valid. Even if not in its literary sense, this warning applies to all nations, to us and to whomever will come after us. The preservation and care deserved by human history and also by histories closest to us-I am referring to such many private archives still hidden in old wardrobes-must become a common rule. For many years, archivists have greeted new technologies with suspicion and resistance, certainly due to distrust in methods that were considered short-lived or otherwise limited. As well as distrust, those who are engaged in this field of work naturally find it inconvenient to adopt new toys and develop new professional skills. What was widely debated was how to find a standard model for storage-that is, a second level of storage. Storing and cataloging images is relatively straightforward, but this is not the case with historical documents. Just consider how difficult it is for a student to find a document in a historical archive for the first time: each archive follows its own logic, the logic of its custodian. The first problem to solve is to ensure that the collection and digitalization of documents follow standard rules. While digitization has made this work faster and easier, archives remain an unsolved problem. Dissemination of information through the web as well as its coordination are the issues addressed by various European projects such as APEnet (2009-2012) and APEx-Archives Portal Europe Network of Excellence (2012-2015), which developed the European Archives Portal (Fig. 4) where the archival resources of various countries are transferred. (Italy is a Content Provider through the State Archives Information System-SIAS.) The European Portal in turn is a partner of Europeana ${ }^{1}$, another important project of the European Commission, aimed at ensuring a single point of access to the entire patrimony of libraries, archives, museums and online audiovisual collections ${ }^{2}$.

Europe is working to find the system or systems to share and improve access to cultural heritage in all its forms. The next step is to ensure the continued relevance of those systems. If on the one hand these tools allow us to save and transfer data with great speed, on the other hand we will need to update them eventually. This is the main problem that we experience in relying on technology. These tools alone are extremely fragile and grow rapidly obsolete. We need to reflect on the damage that can be done if you believe that new tools are the complete solution. We are faced with the obsolescence of programs, sometimes combined with non-compliance with shared standards, as discussed previously, or the loss of institutional knowledge of older systems (see the example of the diagnostic considered in section 4); any one of these problems may cause the loss of data. A debate went on for years and did also produce interesting progress, with international projects aimed at modeling technological standards and standardized rules.

\footnotetext{
${ }^{1}$ http://www.europeana.eu/portal/en

${ }^{2}$ http://archivi.beniculturali.it/index.php/archivi-nel-web/apex-portale-europeo-degli-archivi
} 

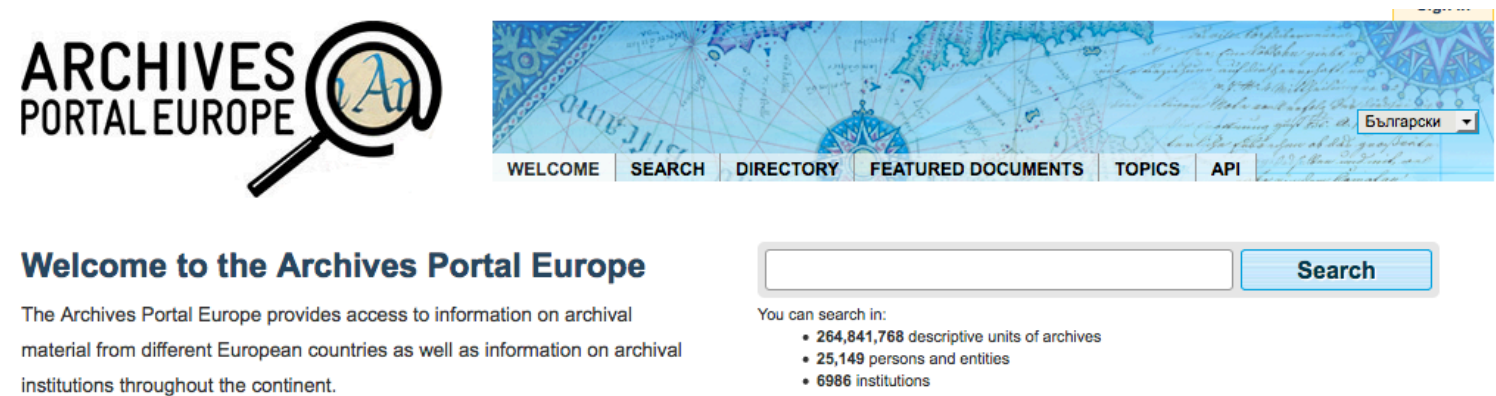

institutions throughout the continent.

Search

25,149 persons and entities
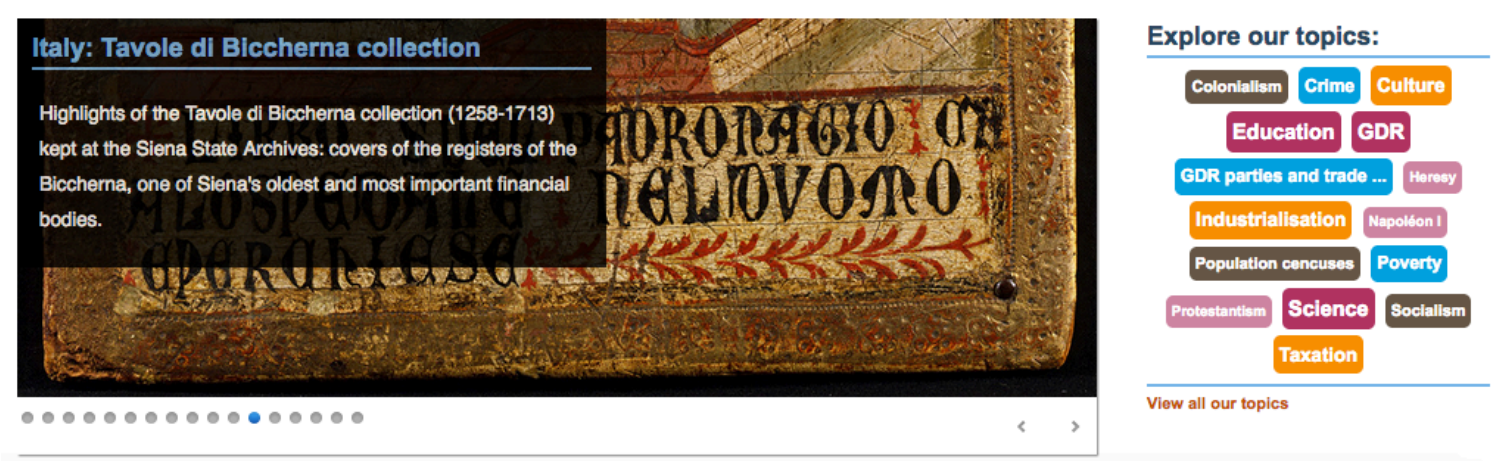

Vlew all our topics

Figure 3. The home page of the "Archives Portal Europe" (https://www.archivesportaleurope.net).

Only practice-and, above all, collaboration between those archivists and technicians who have the delicate task of planning and designing systems-can entrench progress. Communicate to preserve: this is the rule.

\section{PRESERVE}

\subsection{Encyclopedic Palace}

Human beings have always tried from their origin to leave a trace of themselves. Reading a text on archives is sufficient to become aware that man has always had an almost obsessive need to sign, collect and accumulate. Every culture, every people whose relics survive today, has used all its faculties to recount itself, from its everyday life to the great act of kings to the adventures of individuals. The great archives of old times of which we now can read only fragments are the immediate demonstration of this truth. Nothing and nobody want to be forgotten. Collect, accumulate, preserve. "It seems that the museum is a form congenital to the European man, for whom the need to collect precious things for his memory and to store them in a suitable place, has always been a necessity. A dialogue between life and death: to defend objects from death (meaning their disappearance or dispersion); to collect in order to leave memory of oneself; to give new life to these objects by repairing them from the memory of old destruction and damage" [Mottola Molfino 
1991]. These collections in turn respond to another need of human beings, to achieve some sort of universal knowledge. Massimiliano Gioni, presenting the 2013 Venice Biennale, said: "The dream of a universal and all-comprehensive knowledge goes through the history of art and humanity and links eccentric characters like Auriti to many artists, writers, scientists and prophets who have tried, often in vain, to build an image of the world capable of comprehending its infinite variety and richness" [Cavallarin 2014].

The "Encyclopedic Palace" - title of the exhibition - was patented in 1995 by the Italo-American artist Marino Auriti (1891-1980) as an imaginary museum, a 136-storey building, 700 meters high, for an extension of 16 blocks in Washington, which was supposed to comprehend all the knowledge of humanity. "Today, dealing with the flood of information, these attempts to structure the conscience" - knowledge we add - "in all-encompassing systems appear to us even more necessary and even more desperate" [Gioni 2013]. Here come all attempts to save and isolate all our knowledge in all its forms. Just a quick search on the web in order to realize that the effort is a real one: "Omnia omnibus omnino," future didactics meant for everyone and, above all, finally accessible. We all agree in saying that "information does not mean knowledge" [Krajewski 2013]. This is why the next step is supposed to be elaboration, according to tastes and inclinations of each of us. The personalization of perception through an individual codification dictated by experience.

\subsection{The virtual museum}

The museum was born as a public institution aimed at conservation and education. Today that aim has not changed, but nonetheless the institution has had to reinvent itself. We no longer speak of the construction of additional and more beautiful and sophisticated containers, nor of new theories to be realized in order to satisfy the public at large. This new era requires the old museums, and all their apparatuses, to make themselves increasingly accessible to the general public. Today's user can well define himself as a hybrid between analog and digital, between real and virtual, and the museum must therefore accept and satisfy both. Many museums have already begun to digitize their collections for academic and security reasons. Institutions have responded positively to new media, using them as tools for protection and storage, yet this huge amount of data must now be accessible to everyone.

The crucial problem has become converting all this data into accessible, understandable, and attractive formats. The first results of this work were a large number of presentations and web specials online. The "virtual museum," however, was often little more than a database. The works were often available only in low resolutions. While the sites offered presentations dedicated to exhibitions or individual artists, only rarely did they show the full collection. At a time when the distribution of content is so simple, popular opinion favors free access (without, of course, violating copyright rules). Unfortunately, this attitude is not yet unanimous, and even though many museums

\footnotetext{
${ }^{3}$ Marino Auriti (1891-1980) was an Italo-American artist, who escaped fascist persecution. Moving with his family in Pennsylvania, passionate to mechanics and architecture, self-taught, interested in art in all its forms, in the 50s he developed the project of an architectural structure that would host all the achievements of humanity, from wheel to satellite, from handicrafts to avant-garde art works, building a scale model - a 136-storey skyscraper, 700 meters high and divided into 16 blocks in the center of Washington, DC - currently exhibited at the Folk Art Museum in New York. Utopia of a globalized knowledge and the possibility of regulating and cataloging its infinite variety [Treccani 2018].
} 
and archives possess large quantities of copyright-free material, only a few have begun to make it available. Rijksmuseum in Amsterdam, for instance, launched the Rijksstudio in 2012, which allows free access to pieces in its collection: "Users can interact with them, 'like' them, share them with others and use them in any way they wish-and more. Rijksstudio invites the public to enjoy and explore the images: zoom in, save, manipulate, and share. Users are encouraged to download the images and to do something-anything you like-with them. Based on their own special interests, site users can create personal collections, saving either complete images or interesting details. This function is broadly similar to Pinterest." At the presentation of the project, Taco Dibbits, then director of the collections, and since 2016 director of the museum, justified the democratization of the collection: "We believe in the strength of our masterpieces. We also believe that they belong to everyone, and that there is an artist in all of us" [Gorgels 2013]. This rather unusual opening answers the need of museums to become visitor friendly, to open a virtual facsimile, the "virtual museum": closer to the user, full of corridors, details and information, that its real counterpart may not offer, creating a new empathy between new virtual visitors and institutions.

Visiting a virtual museum is not necessarily a passive activity: a virtual museum may allow a user to curate their own gallery of images according to their own sensibility. The concept of "participatory culture" [Giaccardi 2012], intended as a reformulation of the understanding and experience of our heritage, is now dominant. New models of representation and communication answer the needs originated by huge social changes, such as by social media, which implement a new model of aggregation, virtual but real at the same time: we are talking about Pinterest or Instagram. This free acceptance of a new way of enjoying art, of looking towards the group of non-professional enthusiasts, "culture snackers"[Junko 2017], the digital counterparts of cultural tourists, is further facilitated by the new online platforms that make research simpler. Google Art Project, for example, is a search engine with access to a huge number of museums, private collections and state archives; Emuseum.net allows us to browse sites in order to discover information and works of a particular artist, see the images, and find the museums where their works are collected. Today one may also track auction prices or become a collector with Artsy, Artprice, Artnet, and ArtValue, through which you can learn about and involve yourself in the complex and volatile world of art market. These are the new paradigms for the diffusion of art and culture: immediate, involving, and editable according to one's own inclinations.

The obstacles for the realization of virtual projects are mainly financial, at least at the beginning. For example, a country like Italy should materially digitize itself, but a digital encyclopedia faces administrative and bureaucratic difficulties, not to mention questions of competence or professionalism. Given that the digitization of our assets is now routine, cultural institutions, either museums, libraries or archives, must overcome the purely administrative purpose of communicating with the public, continuing to tell stories and to present educational routes. Following international guidelines also in our country we tried to better codify a model and a kit, CMS MOVIO [Caffo and al. 2011] for public and private institutions for the realization of these virtual projects. This document, born from the cooperation between the Central Institute for the Italian libraries database - ICCU and the Central Institute for Archives - ICAR, in collaboration with the Technological Observatory for Cultural Heritage and Activities-OTEBAC, both illustrates the state of the art of virtual exhibitions and suggests guidelines. The guidelines, which are also a contribution to the European project 
INDICATE [INDICATE 2012], are the result of a debate among experts and operators from the different sectors of cultural heritage who shared their experiences in a dedicated working group. The digital exhibitions are an effective learning tool, which offer more materials than a real exhibition or museum department could. Not only are they superior in the quantity of items offered, their users can dwell on details of particular items, which is impossible in overcrowded exhibition spaces, for as long as they wish.

Virtual visits to famous museums are a great opportunity: you can look at and browse the works from various points of view, perhaps with a voice or a text that makes you grasp what may go unnoticed in a normal visit. A visit to a real exhibit ordinarily entails a struggle to observe objects on display amid chattering and jostling crowds, or to read minuscule, often irrelevant or shallow labels. Looking and travelling from home can be the true luxury given us by technology. But what happens if the experience becomes increasingly passive? If your eye is no longer looking, it becomes only an organ of perception. If you only see what you are told to see, can you build up a true personal and critical judgment? And furthermore, will all this accessible knowledge tend to isolate man? Is this delusion that we are able to see everything, to be able to go anywhere, to be part of a group, to share, not limiting in itself? Does it generate a vacuous satisfaction? I am mainly referring to the new generations, who do not know what it means to touch the pages of an encyclopedia or to make a music box using the play + rec keys. To read a map or organize a trip driven by the pure taste of discovery (they have already seen everything). We run the risk of perceptual atrophy. We shall not give up the exercise of knowledge.

\section{SAVING}

"Inside Caravaggio" is the title of the study days that followed the closing of the exhibition held in Milan (Palazzo Reale, September 20th, 2017 - February 4th, 2018). The exhibition was a great success due to the large number of visitors $(400,000)$, but above all for the contribution given by scientific and documentary discoveries, which of course gave rise to new issues. Not only did the visitors have the possibility of looking at many beautiful masterpieces very well laid out, they were also able to better understand and appreciate the great artist thanks to scientific tools: all the works were accompanied by their respective X-ray. This result would not have achieved without the contribution of image technicians to the curator's work.

On the second day of studies, we listened to the speech of Isabella Castiglioni, a researcher of CNR (Italian National Research Council) Institute of Bioimaging and Molecular Physiology of the Department of Nuclear Medicine at St. Raffaele Hospital of Milan. The speech "Processing diagnostic images of art: a survey instrument," explained that all diagnostic techniques used in medicine, from fluorescence imagines, ionizing radiation, magnetic ultrasound or X-rays, with the exception of those which use contrast agents, can be used for art research. And that post processing, which is the methodology that can be used once all diagnostic images have been gathered, is presently also used with the same purpose. Nowadays, we no longer consider exclusively the qualitative result of the images detected (as in X-rays) but we may also elaborate the images using numeric parameters which can be compared timely. We are now using the same sophisticated techniques and expertise used in medicine using the same technological skills. The results of these studies are very interesting

Studies in Digital Heritage, Vol. 2, No. 1, Publication date: September 2018 
from a scientific viewpoint and can be used for education and explanation purposes, for instance in art exhibitions or in video representations. One example is the video made of the Peruzzi Chapel in Santa Croce church in Florence, presented during the "Giotto, l' Italia. Da Assisi a Milano" exhibition at Palazzo Reale in Milan in 2015. The result of a very complex fluorescence and diagnostic campaign, using compensatory techniques such as cloning and correction of the collected material, which consisted of a thousand ultraviolet light and natural light frames, is a fascinating three-dimensional video, which also reconstructs in light fluorescence the missing parts of the decoration.

As in medicine, where three-dimensional renderings are created to help supporting surgery or radiotherapy, with this video the experts have reproduced the visual experience of the Giotto frescos, a virtual restoration also for non-experts. This is the great contribution of technology: it helps us to see what time, negligence and fragility have taken away.

The use of diagnosis in art research is not altogether new. Indeed, X-ray tubes were already used in 1930 and 1940. Cesare Brandi ${ }^{4}$ [Brandi 1963] did use spectrographic analysis for the study of works of art to be restored. The results of those scientific analyses have produced a lot of material, stored in museums and archives, having however the defect of not being easily understandable in a modern sense. This is one of the biggest challenges that art historians must face when they analyze images of the past: that of finding the correct way to understand them in order to compare with present material.

The modern techniques help us to better understand the artist: procedures, techniques, materials, pigments. All of these documents are a key for historians and restorers who risk, due to lack of knowledge, to permanently damaging masterpieces. Presently, thanks to the modern tomographic instruments, which can analyze the minimal surfaces, invasive microscopic analysis can now be avoided. The technical knowledge which is of great use for art historians and restorers, must now also be shared and communicated to the public. The deeper knowledge on the masterpiece, can help us to further understand and appreciate the artist. We feel closer to the artist and better understand his methods, doubts, re-thinking and tricks-in Caravaggio's case, for example, "profili a risparmio" and "preparazione a vista" [Vodret 2017] were used to accelerate his work. Historical research, style analysis and diagnostic techniques must integrate and combine themselves. This is a challenge and an effort leading us to new models for understanding art.

\section{COMMUNICATING}

\subsection{Lo stupore e la bellezza ${ }^{5}$}

By retracing the history of art, the use that man has made of images becomes quite evident. Images are never a goal in themselves, but they were always meant to communicate, to remember, and to

\footnotetext{
${ }^{4}$ Cesare Brandi (Siena, 1906 - Vignano, 1988) was an art historian and critic, specialized in conservation and restoration theory. In 1939 he founded the Central Institute for Restoration (now the Italian Institute for Conservation and Restoration) in Rome. His most important work, Theory of Restoration, is a key text and still a reference for this discipline. Brandi was a proponent of the "tratteggio," a controversial method of pictorial reintegration through thin dashed lines in watercolor.

5 "Lo stupore e la bellezza" [Kermani 2017], is the Italian title of David Kermani's book "Ungläubiges Staunen: Über das Christentum" [Kermani 2015].
} 
provoke. All peoples, kingdoms, religions, and cultures whose artifacts still exist have deliberately left memories of themselves by means of images. Studying and above all understanding the history of art means knowing and understanding the history of mankind.

The relationship between art and theology, for instance, has ancient roots. Christianity has from its beginning employed images to tell, and make people talk, about itself. After a short aniconic period, art and religion have walked together throughout history. Art has described dogmas and mysteries by means of images following its own aesthetic and expressive canons that cannot however be studied and understood without a careful historical analysis.

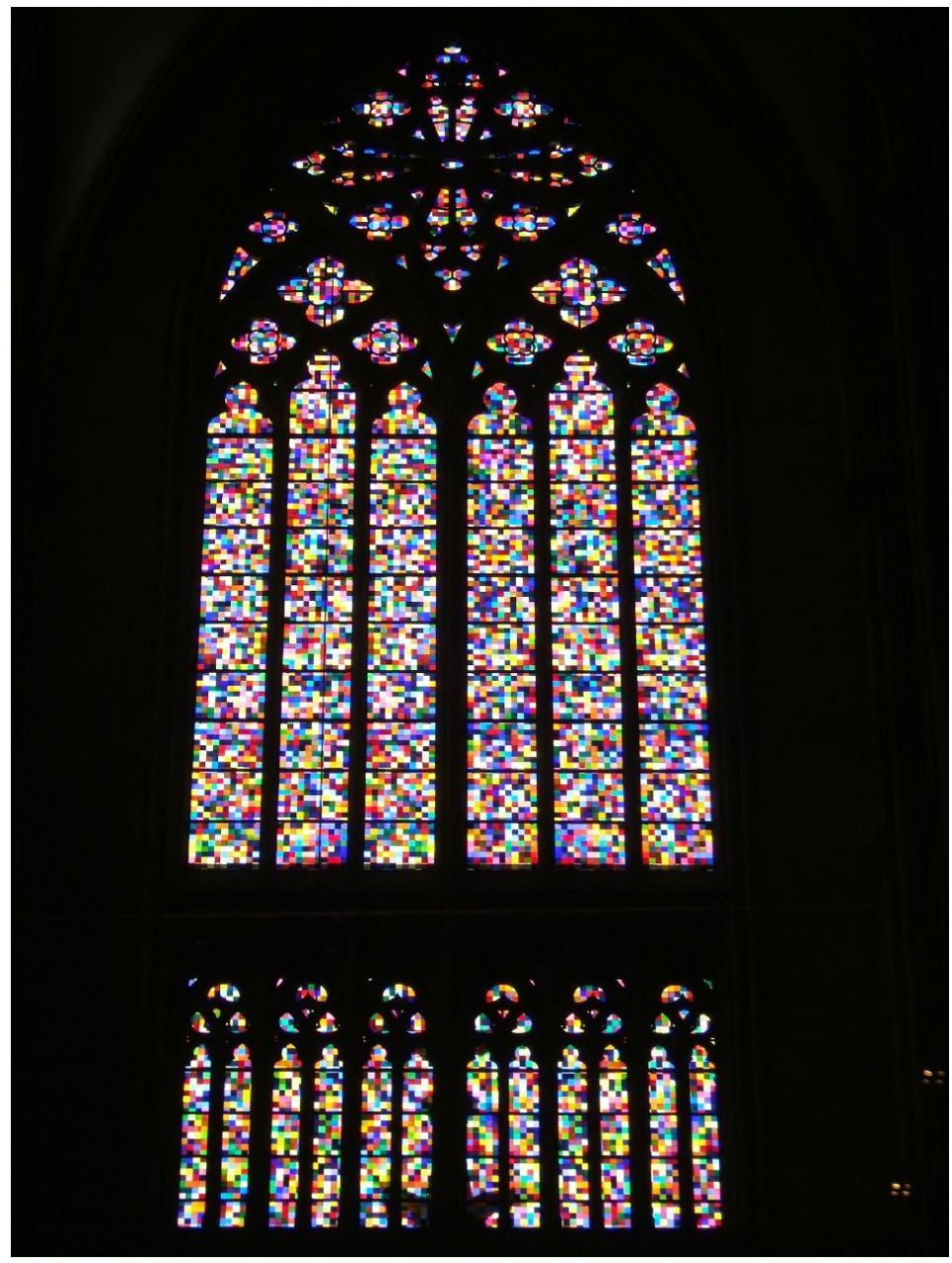

Figure 4. Stained glass window of the Cologne Cathedral, 2007.

In the case of Christian religion, since the scriptures are stories of human events, their representation also attracts those who seem to be devoid of any knowledge of its iconography. The image has always been a strategic expedient to transmit and spread dogmatic messages. We believe, however, that representation in any case requires knowledge and does not live independently. "Words, in fact, 
enunciate, declare, explain and clarify, while the holy image is essentially made to show, attract, call attention to, change view, sometimes provoke, convert and comfort" [Fogliadini 2015]. The usefulness of images seems very clear from the beginning; the service given to the diffusion of Christian religion is quite evident. Every age has left great works of brilliant artists who have served with their inspiration and their manners to the "social" and "political" needs of the Church. In reading these works we can understand the needs that the Church did have in that historical moment. From the hieratic distance of the medieval teaching Church to the tale, almost didactic, of the scriptures typical of the first Renaissance until the symbols and the epic triumphs of the Baroque used by a somewhat weaker and less belligerent Church. "The Church felt the need to involve everyone in its reform and stimulated the birth of an aesthetic language that could drag them all, rich and poor, educated and illiterate. Less was written, and more was composed: theatre, music and scene were assembled in order to create a unique work of art" [Daverio 2017].

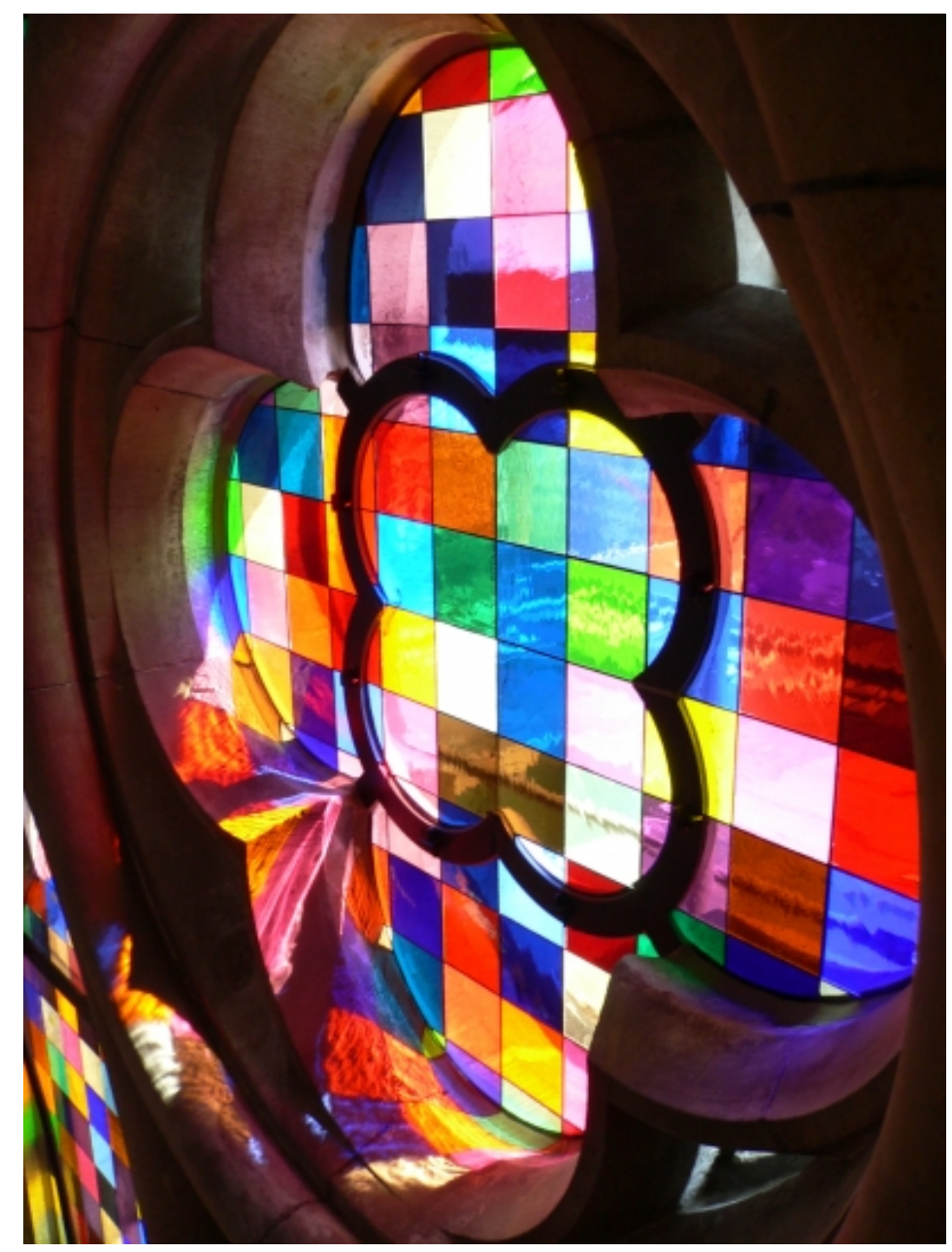

Figure 5. Stained glass window of the Cologne Cathedral, 2007. 
Coming to the present days, we are considering the new window of the Cologne Cathedral, designed by Gerhard Richter (Fig. 4 and 5). The artist worked for four years in studying colors to be used for his stained-glass windows. The work was not easy, and he did work with other experts (physicians and programmers) to create 72 colors for 72 diamonds: 5184 pieces of colored glass. An enormous window work (13 square meters) which is entirely made of light. It is full of knowledge, but at the same time it does deny the human"[Kermani 2017]. The Cologne Cathedral has found, thanks to Richter and of course its patrons, a new light and a new life. If the cathedral is the symbol of a community and of its history, with this operation the symbol became modern: "Richter's pieces radiate XXI century" [Kermani 2017]. These lines have certainly oversimplified the deep meaning that images have had for religion and vice versa, but they may be useful to justify and understand the way in which we are using them presently. Communicate by images helps to stimulate perceptions and emotions, as well as to remind and to transmit the enormous baggage of our cultural memories.

\subsection{The multimedia exhibitions}

A new aesthetic of information, what Lev Manovich calls "Info-aesthetics," is ascendant. "The discipline of info-esthetics studies how the contemporary culture responds to the challenge of managing, storing and circulating growing quantities of data that leads to new aesthetic sensitivity and communication forms and strategies, from design to architecture, from cinema to the design of human-computer interfacing" [Garassini 2005]. A format that is having great success with the public in recent times is the "exhibition-event," considered by many close to the "blockbuster exhibition" for which Italy is famous, and on which several articles and critical pamphlets have been written [Montanari and Trione 2017]. This due to their model, ostensibly democratic, but above all quite smart in simulating culture. The format of these exhibition-events offers only star artists, whose universal knowledge guarantees easy media communication, becoming practically "brand" artists [Montanari and Trione 2017]. These exhibitions do offer the opportunity to see works coming from private collections or from foreign museums. However quite often they have been assembled in an unscientific and superficial manner. This does not mean that they do not leave a pleasant memory and also the feeling of having learned something. The proliferation of these exhibitions-events is probably due to an institutional void that should be filled by museums. There is a lack of ideas and money, but above all the courage of changing language is missing. If the institutions rightly do not want this change, which would cancel their role, they do not always refuse the idea of an "explant" of works in exchange for money. They are colluding with these novelties. We are witnessing the devaluation of great artists for purely economic reasons. We agree with the intellectuals and historians who refuse this type of exhibition, little study and much profit, with a greater risk for the works borrowed: out of context, delicate and unique.

In addition to the exhibition-events, we are invited to attend another model of exhibition, this time without works, the "multimedia exhibitions": in 2015, Van Gogh 3D and The Caravaggio Experience; in 2017, The Klimt Experience; in 2018, The Da Vinci Experience and Giudizio Universale: Michelangelo and the Secrets of the Sistine Chapel. We are speaking here of actual shows and allencompassing experiences. Technology comes into play here. Thanks to it we can enter the world of an artist among his characters, in his reality or fantasy, with amazement and wonder just as the populace did in entering the churches (Fig. 1 and 2) or witnessing the baroque fantasies. A total 
immersion in music and images, a dreamlike and amazing experience. How, then, should we react to the criticisms that these new formats also attract? The problem, in my opinion, lies in confusing these events with exhibitions. Let's call them happenings or shows, and let us keep them, but in other categories, as we already do. The exhibitions must be made by museums: this is the point. We must find a way to give a new start to scientific and cultural exhibitions with the continued financial support of institutions. This is the main problem. Shows are negative only when they replace another kind of thing, but the fact is that those who produce them have no such intention. The defect lies in the intellectual limitation of not being able to make them live together. They are two distinctive things, having different aims with very different projects and aimed at different users. They may very well be considered complementary because they satisfy a large margin of public. The work of art exists when a relationship with the user is created. This is why this experience is subjective and changeable, reflects emotions and moods. In the case of multimedia exhibitions, aesthetic judgments are not required, but only the usage of sensory stimuli that are variable and not classifiable. We do not ask for a critical judgment with all its implications, but a simple aesthetic pleasure according to our idea of beauty, through our personal filters. Doctrines prove the existence of different degrees of enjoyment. The observation of an object of art is never a pure one, devoid of relationships, because we have always been accustomed to classifying what we see or touch. This model of perception is the result of our culture. Accordingly, if we watch a multimedia exhibition, that with amplified sounds and images stimulates our senses in an engaging way, our first contemplative state immediately becomes fruition as well as "a real performative action. This must be understood in the etymological sense of the word, as an action that creates meaning and contents: no longer a simple act of observing a work of art, but a communicative-didactic action between two elements, user and work, subject and object of interaction" [Finocchi 2011]. Naturally this is valid from the more or less didactic essence of the experience and from the intentions of the production itself.

To think that the number of art lovers is limited to few people is a mistake. If these new media may in their own way teach something more, then they are welcome. At bottom, they are entertainment, which in our opinion always has a performative value. Consider the younger generations, who are filled with information and images the size of a tablet screen: the "multimedia" exhibition for them can have a great aesthetic and educational effect. A beautiful immersion in sound and color can only leave feelings, emotions and memories more alive, an experience that as such is always positive and always enriching. We are witnessing a real change in cultural communication strategies. If these new strategies are the answer to a widespread impoverishment of interest in the containers of knowledge (museums and libraries), then why not leave them aside, with new means of expression and education at the same time.

\section{CONCLUSIONS}

2018 is the European Year of Cultural Heritage, whose guidelines are given by the European Community site: "The European Year of Cultural Heritage will highlight the richness of Europe's cultural heritage, highlighting its role in promoting a shared sense of identity and building the future of Europe." The collective memory, the European identity is hidden among the stones of the archaeological sites, among the battlements of the medieval castles, in popular traditions and in the arts. All this wealth is then a source of economic growth, development and exchange with the rest of

Studies in Digital Heritage, Vol. 2, No. 1, Publication date: September 2018 
the world. There is a new awareness of values ??and of the value of our cultural heritage," in particular at a time when cultural treasures are threatened and deliberately destroyed in conflict zones" [EU 2017], the site still reads. We must protect and preserve our riches as best we can, because "the attempt to abolish and erase the memory of humanity is the worst crime for humanity" [Daverio 2017]. We can do it with the help of technology.

\section{REFERENCES}

Richard Adler, 1997. InfoWorld Futures Project interview to Paul Saffo. InfoWorld. Retrieved Sept 2018: http://www.saffo.com/interviews/infoworld-futures-project-interview

Cesare Brandi. 1963. Teoria del restauro, Einaudi.

Rossella Caffo, Tatiana Anderlucci, Viviana Carini, Laura Ciancio, Alfredo Corrao, Alfredo Esposito, Tiziana Fabris, Giuliano Granati, Valentina Grippo, Cristina Magliano, Adriana Martinoli, Marina Morena, Maria Teresa Natale, Elisabetta Pagani, Paola Panaccio, Elisa Sciotti, Priscilla Sermonti, and Giuliana Zagra. 2011. Mostre Virtuali on-line: linee guida per la realizzazione. Retrieved September 2018: http://www.otebac.it/index.php?it/320/mostre-virtuali-online-linee-guida-perla-realizzazione www.movio.beniculturali.it/getFile.php?id=57

Eugenio Casanova. 1928. Archivistica, Stabilimento Arti Grafiche Lazzeri. Retrieved January 2018 : http://www.icar.beniculturali.it/biblio/pdf/EuCa/totalCasanova.pdf

Martina Cavallarin. 2014. L'esperienza della visione. Retrieved Jan 2018: https://www.wikieventi.it/milano/amp.php?id_evento=77418

Philip Daverio. 2017. L'arte di guardare l'arte, Giunti.

EU. 2017. L'Anno europeo del patrimonio culturale 2018 prende il via. Retrieved January 2018: https://ec.europa.eu/italy/news/20171207_anno_europeo_patrimonio_culturale_it

Valeria Finocchi. 2011. Il valore performativo della fruizione artistica. Retrieved June 2018 http://ww2.unime.it/mantichora/wp-content/uploads/2012/01/Mantichora-1-pag-277-286Finocchi.pdf

Emanuela Fogliardini. 2015. Teologia, cristianesimo e arte. Retrieved January 2018 : http://www.teologiamilano.it/teologiamilano/allegati/258/09.TEOLOGIA\%20CRISTIANESIMO\%20 E\%20ARTE.pdf

Stefania Garassini. 2005. Lev Manovich: la nuova estetica dell'informazione. Retrieved in January 2018: http://manovich.net/index.php/projects/domus-2005-italian

Elisa Giaccardi. 2012. Heritage and Social Media: Understanding heritage in a participatory culture, Routledge.

Massimiliano Gioni and al. 2013. Palazzo Enciclopedico (The Encyclopedic Palace), Published on the occasion of the exhibition Il Palazzo Enciclopedico, the 55th International Art Exhibition of La Biennale di Venezia, June 1-November 24, 2013, Marsilio.

Peter Gorgels. 2013. Rijksstudio: Make Your Own Masterpiece! Retrieved January 2018:

https://mw2013.museumsandtheweb.com/paper/rijksstudio-make-your-own-masterpiece/

INDICATE. 2012. Retrieved in February 20018 http://www.indicate-project.eu/index.php?en/94/about Junko. 2017. We are Culture Snackers. Medium. Retrieved September 2018

https://culturesnackers.com/we-are-culture-snackers-4e988d7e3739

Navid Kermani. 2015. Ungläubiges Staunen: Über das Christentum, München, 303 Seiten. ISBN 978- 
3-406-68337-4.

Navid Kermani. 2017. Lo stupore e la bellezza. Meraviglia e bellezza dell'arte cristiana, Marsilio. Markus Krajewski. 2013. In Massimiliano Gioni and al, Palazzo Enciclopedico, (The Encyclopedic Palace), Published on the occasion of the exhibition Il Palazzo Enciclopedico, the 55th International Art Exhibition of La Biennale di Venezia, June 1-November 24, 2013, Marsilio. Tommaso Montanari and Vincenzo Trione. 2017. Contro le mostre, Einaudi.

Alessandra Mottola Molfino. 1991. Il libro dei musei, Allemandi.

Treccani. 2018. Auriti, Marino. Treccani Encyclopedia. Retrieved September 2018 http://www.treccani.it/enciclopedia/marino-auriti/

Rossella Vodret. 2017. Dentro Caravaggio (Inside Caravaggio), Catalogue of the exhibition "Dentro Caravaggio" held at Palazzo Reale, 2017-2017, Milano, Skira, 2017.

Received February 2018; revised September 2018; accepted September 2018. 